\title{
ADAM12 silencing promotes cellular apoptosis by activating autophagy in choriocarcinoma cells
}

\author{
LIN WANG $^{1}$, ZHIHUI TAN ${ }^{2}$, YING ZHANG ${ }^{2}$, NANKORIA KADY KEITA ${ }^{2}$, HUINING LIU $^{2}$ and YU ZHANG ${ }^{2}$ \\ Departments of ${ }^{1}$ Cardiovascular Surgery and ${ }^{2}$ Gynecology, Xiangya Hospital, \\ Central South University, Changsha, Hunan 410078, P.R. China
}

Received September 16, 2019; Accepted January 17, 2020

DOI: $10.3892 /$ ijo.2020.5007

\begin{abstract}
ADAM metallopeptidase domain 12 (ADAM12) has been demonstrated to mediate cell proliferation and apoptosis resistance in several types of cancer cells. However, the effect of ADAM12 silencing on the proliferation and apoptosis of choriocarcinoma cells remains unknown. The present study revealed that ADAM12 silencing significantly inhibited cellular activity and proliferation in the human choriocarcinoma JEG3 cell line and increased the rate of apoptosis. In addition, ADAM12 silencing significantly increased the expression levels of the autophagy proteins microtubule-associated protein-light-chain 3 (LC3B) and autophagy related 5 (ATG5) and the fluorescence density of LC3B in JEG-3 cells. However, the suppression of autophagy by 3-methyladenine could block ADAM12 silencing-induced cellular apoptosis. ADAM12 silencing reduced the levels of the inflammatory factors interleukin-1 $\beta$, interferon- $\gamma$ and TNF- $\alpha$, and inactivated nuclear p65-NF- $\mathrm{B}$ and p-mTOR in JEG-3 cells. The downregulation of $\mathrm{p}-\mathrm{mTOR}$ expression by ADAM12 silencing was rescued in 3-methyladenine-treated JEG-3 cells, indicating that mTOR might participate in the autophagy-mediated pro-apoptotic effect of ADAM12 silencing. In conclusion, ADAM12 silencing promoted cellular apoptosis in human choriocarcinoma JEG3 cells, which might be associated with autophagy and the mTOR response. These findings indicate that ADAM12 silencing might be a potential novel therapeutic target for choriocarcinoma.
\end{abstract}

\section{Introduction}

Choriocarcinoma is a highly malignant tumour that develops from trophoblast cells and usually occurs in the uterus, and it can cause severe local damage and metastasize to other areas

Correspondence to: Dr Zhihui Tan, Department of Gynecology, Xiangya Hospital, Central South University, 87 Xiangya Road, Changsha, Hunan 410078, P.R. China

E-mail: tanzhihui@csu.edu.cn

Key words: ADAM12, choriocarcinoma cell, proliferation, apoptosis, autophagy of the body (1). As the clinical presentation of choriocarcinoma may vary, diagnosis may be challenging and the prognosis of patients with choriocarcinoma is related to the clinical stage and trophoblastic activity $(1,2)$. It is widely recognized that the regulatory process of trophoblast invasion may be associated with growth factors, chemokines, protein kinases and signaling pathways, and the changes in the regulation of these factors may lead to various pathological changes (3). Therefore, a deeper understanding of the mechanisms underlying cell proliferation and apoptosis in choriocarcinoma is required to develop novel treatment strategies and improve patient prognosis.

The disinterring and metalloprotease (ADAM) family consists of several type I transmembrane proteins that have been widely reported to be involved in various physiological functions, such as cell-binding and intracellular signalling, related to human tumour metastasis $(4,5)$. Members of the ADAM family have two major structural regions, the de-integrin and the metal matrix protease regions, which degrade the extracellular matrix and control cell adhesion and movement by regulating cell adhesion and protease activity (5). Among the members of the ADAM family, ADAM metallopeptidase domain 12 (ADAM12) expression is highly associated with several types of epithelial cancer, including breast, skin, ovarian, stomach, lung, prostate and brain cancer (6-10). ADAM12 contributes to cell differentiation, tumour cell proliferation, migration and invasion (8,11-18) as well as apoptosis and endocrine resistance (19). Apoptosis is a well-known form of programmed cell death and is a highly regulated and controlled process. Autophagy allows the removal of unnecessary or dysfunctional cellular components and allows the orderly degradation and recycling of cellular components (20-22). Both apoptosis and autophagy are known to play roles in several diseases, including cancer (23-26). However, the specific role of ADAM12 silencing in the apoptosis and autophagy of choriocarcinoma cells, as well as the related mechanisms, has not yet been described. Therefore, the present study investigated the effects of ADAM12 silencing on the proliferation and apoptosis of the human choriocarcinoma JEG-3 cell line. Additionally, the potential mechanisms involved in autophagy and other signalling pathways were explored in JEG-3 cells following ADAM12 silencing. 


\section{Materials and methods}

Cell culture and transfection. The human choriocarcinoma JEG-3 cell line was acquired from the Cell Bank of Type Culture Collection of the Chinese Academy of Sciences (27). The cells were cultured in DMEM medium (Gibco; Thermo Fisher Scientific, Inc.) supplemented with $10 \%$ fetal bovine serum (Gibco; Thermo Fisher Scientific, Inc.) and maintained in an incubator containing $5 \% \mathrm{CO}_{2}$ at $37^{\circ} \mathrm{C}(28)$. ADAM12-small interfering RNAs (ADAM12-siRNA; target 1, 5'-GCCTGAATCGTCAATGTCAAA-3'; target 2, 5'-CGCTCGAAATTACACGGTAAT-3'; and target 3, 5'-GCG AGATGAGAGATGCTAAAT-3') were synthesized by Shanghai GeneChem Co., Ltd. The siRNA targeted transcript variant 1 (NCBI Ref. Seq. NM_003474) of ADAM12 was used. In addition, scrambled-siRNA (non-targeting sequence, 5'-CCTAAGGTTAAGTCGCCCTCG-3' (also synthesized by Shanghai GeneChem Co., Ltd) was used as a negative control (si-NC). A blank control (BC) group, consisting of untransfected JEG-3 cells, was also set up. Transfection was performed using Lipofectamine ${ }^{\mathrm{TM}} 2000$ (Thermo Fisher Scientific, Inc.) according to the manufacturer's instructions. JEG-3 cells culture were observed using an optical microscope (magnification, $\mathrm{x} 200$ ), and the transfection efficiency at $48 \mathrm{~h}$ post-transfection was detected by western blotting. In order to test whether ADAM12-knockout affected autophagy, $10 \mathrm{mM}$ 3-methyladenine (3MA; cat. no. M9281-100 mg; Sigma-Aldrich) was co-applied with siRNA transfection and used for blocking autophagy in JEG-3 cells, the ADAM12-siRNA-3MA group for $24 \mathrm{~h}$.

Cell proliferation. JEG-3 cells in DMEM were seeded in a 96-well plate $\left(5 \times 10^{3}\right.$ cells/well) and incubated for $24 \mathrm{~h}$ at $37^{\circ} \mathrm{C}$. In addition, ADAM12-siRNA, ADAM12-siRNA-3MA and ascrambled-siRNA groups were included. At $24 \mathrm{~h}$ post-transfection, $10 \mu$ l of pre-warmed Cell Counting Kit-8 (CKK-8; Dojindo Molecular Technologies, Inc.) solution were added to each well, and the cells were incubated for $4 \mathrm{~h}$ at $37^{\circ} \mathrm{C}$ and $5 \% \mathrm{CO}_{2}$, and the absorbance values of the cells in each group were measured at a wavelength of $450 \mathrm{~nm}$ using a microplate reader.

Cell cycle analysis. JEG-3 cells were trypsinized to form a single cell suspension and washed 2-3 times with PBS. The number of cells was adjusted to $1 \times 10^{6}$ cells $/ \mathrm{ml}$. The cells were then resuspended in $1 \mathrm{ml}$ pre-cooled PBS and centrifuged at $250 \mathrm{x} \mathrm{g}$ for $5 \mathrm{~min}$ at $4^{\circ} \mathrm{C}$, and the supernatant was aspirated. The cells were gently resuspended with $20 \mu 1$ PBS and incubated with $600 \mu 1$ pre-cooled $100 \%$ ethanol (final concentration, $75 \%$ ) overnight at $4^{\circ} \mathrm{C}$. The fixed cells were centrifuged at $250 \mathrm{x} \mathrm{g}$ for $5 \mathrm{~min}$ at $4^{\circ} \mathrm{C}$, and the supernatant was aspirated. Next, the cells were resuspended in $1 \mathrm{ml}$ pre-cooled PBS, after which they were centrifuged at $250 \mathrm{x} \mathrm{g}$ for $5 \mathrm{~min}$ at $4^{\circ} \mathrm{C}$ and collected. This process was repeated 1-2 times to remove the ethanol. Next, the cells were incubated with $150 \mu 1$ propidium iodide (Sigma-Aldrich; Merck KGaA) for $30 \mathrm{~min}$ at $4^{\circ} \mathrm{C}$ in the dark. The cells were subsequently analyzed using a CytoFLEX $\mathrm{S}$ flow cytometer (Beckman Coulter, Inc.) and CytExpert software (version 2.0; Beckman Coulter, Inc.). The percentage of cells in each stage of cell cycle was analyzed.
Flow cytometry detection of the apoptosis rate. The transfected and control JEG-3 cells were collected by trypsin digestion without EDTA, washed twice with PBS and centrifuged at $4^{\circ} \mathrm{C}$ for $5 \mathrm{~min}$ at $520 \mathrm{x}$ g. Approximately $1-5 \times 10^{5}$ cells were collected. Then, $500 \mu$ l binding buffer was added to the cell suspension. The cells were incubated with $5 \mu \mathrm{l}$ Annexin V-FITC and $5 \mu \mathrm{l}$ propidium iodide (eBioscience ${ }^{\mathrm{TM}}$ Annexin V Apoptosis Detection Kit FIFC; cat. no. 88-8005-72; Thermo Fisher Scientific, Inc.) for 5-15 min at room temperature in the dark. Apoptotic cells were detected within $1 \mathrm{~h}$ by a CytoFLEX $\mathrm{S}$ flow cytometer (Beckman Coulter, Inc.) and analysed using CytExpert software (version 2.0; Beckman Coulter, Inc.).

Western blotting. JEG-3 cells were treated with lysis buffer (50 mM Tris- $\mathrm{HCl} \mathrm{pH} 7.4,150 \mathrm{mM} \mathrm{NaCl}, 1 \%$ Triton X-100, $0.5 \%$ sodium deoxycholate, $0.1 \%$ sodium dodecylsulfate (SDS), 5 mM EDTA, $1 \mathrm{mM}$ 4-(2-aminoethyl) benzenesulfonyl fluoride hydrochloride, $5 \mu \mathrm{g} / \mathrm{ml}$ pepstatin, $5 \mu \mathrm{g} / \mathrm{ml}$ leupeptin, $5 \mu \mathrm{g} / \mathrm{ml}$ aprotinin and $10 \mathrm{mM} \mathrm{1,10-phenanth-}$ roline) for $30 \mathrm{~min}$ on ice. The samples were denatured by boiling in SDS sample buffer (SDS-PAGE Gel Preparation kit; CWBio). The protein concentration was determined using a BCA Protein Concentration Assay kit (CWBio), and $50 \mu \mathrm{g}$ protein/lane were subjected to SDS-PAGE on 4-20\% Tris-glycine gels and transferred onto polyvinylidene difluoride membranes. The membranes were dyed with $0.1 \%(\mathrm{w} / \mathrm{v})$ ponceau $\mathrm{S}$ for 1-2 min at room temperature and washed. Then, the membranes were blocked with $5 \%$ milk in Tris-buffered saline and $0.1 \%$ Tween 20 (TBST) for $1 \mathrm{~h}$ at room temperature. The membranes were washed with TBST for $5 \mathrm{~min}$, and incubated with primary antibodies (all used at a 1:1,000 dilution) against ADAM12 (cat. no. 14139-1-AP; ProteinTech Group, Inc.), autophagy related 5 (ATG5; cat. no. 10181-2-AP; ProteinTech Group, Inc.), microtubule-associated protein-light-chain 3 [LC3B, detected two bands LC3BI (upper bands) and LC3BII (lower bands); cat. no. 18725-1-AP; ProteinTech Group, Inc.], caspase-3 (detected pro- and cleaved caspase-3; cat. no ab13847; Abcam), caspase-9 (detected pro- and cleaved caspase-9; cat. no. ab202068; Abcam), Bax (cat. no. 50599-2-Ig; ProteinTech Group, Inc.), p53 (cat. no. 10442-1-AP; ProteinTech Group, Inc.), phosphorylated-mTOR (Ser2448; cat. no. ab109268; Abcam), mTOR (cat. no. ab2732; Abcam), p65-NF- $\mathrm{BB}$ (cat. no. 10745-1-AP; ProteinTech Group, Inc.); proliferating cell nuclear antigen (PCNA; cat. no. 10205-2-AP; ProteinTech Group, Inc.) and $\beta$-actin (cat no. 60008-1-Ig; ProteinTech Group, Inc.) overnight at $4^{\circ} \mathrm{C}$. The membranes were washed three times with TBST, $10 \mathrm{~min} /$ wash. Subsequently, the membranes were incubated with goat anti-rabbit $\operatorname{IgG}$ horseradish peroxidase-conjugated secondary antibodies (at 1:1,000 dilution; cat. no. SA00001-2; ProteinTech Group, Inc.) at room temperature for $1 \mathrm{~h}$, and washed three times with TBST, $10 \mathrm{~min} /$ wash. The protein bands were visualized using the SuperSignal West Pico Chemiluminescent Substrate (EMD Millipore). ImageJ software (version 1.8.0; National Institutes of Health) was used to analyze the greyscale values, with $\beta$-actin or PCNA as the loading control. The calculation was performed as follows: The amount of relevant protein expression $=$ (the grey value of measured protein/the grey value of internal parameter). 
A

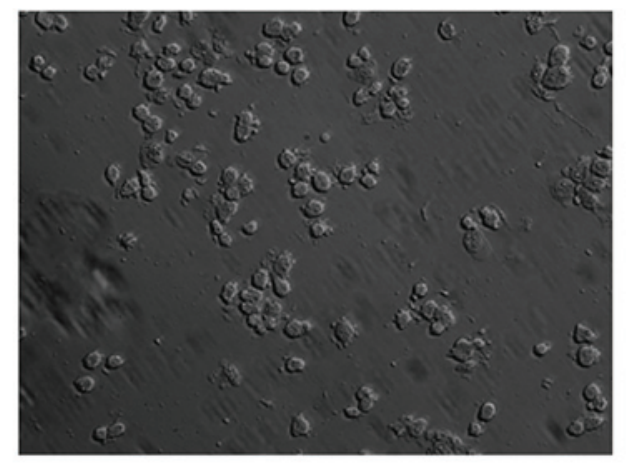

B

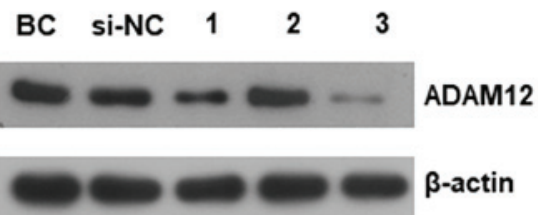

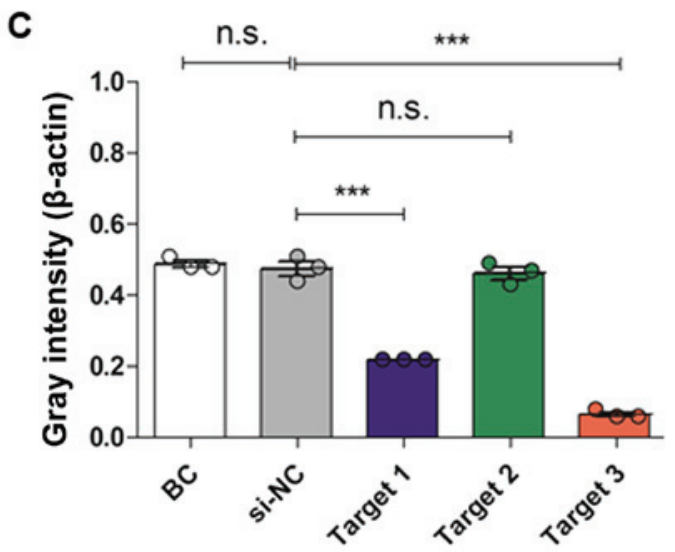

Figure 1. JEG-3 cell culture and ADAM12-siRNA transfection. (A) Untransfected JEG-3 cells observed under an optical microscope (magnification, x200). (B) Western blotting revealed that the levels of ADAM12 protein were decreased after ADAM12-siRNA transfection with three different targets (1, 2 and 3). (C) Quantification of the western blotting showed that ADAM12-siRNA target 3 had the highest transfection efficiency in JEG-3 cells, compared with targets 1 and 2 . ${ }^{* * * *} \mathrm{P}<0.05$, as indicated. ADAM12, ADAM metallopeptidase domain 12; siRNA, small interfering RNA; NC, negative control; BC, blank control; n.s., not significant.

Immunofluorescence. JEG-3 cells were plated onto sterile coverslips and allowed to attach overnight at $4^{\circ} \mathrm{C}$. JEG-3 cells were then washed with PBS and fixed with $4 \%$ paraformaldehyde in PBS (pH 7.4) for $20 \mathrm{~min}$ at room temperature. These cells were washed three times with PBS and permeabilized with $0.1 \%$ Triton X-100 in PBS for 5 min. The cells were then blocked with $1 \%$ bovine serum albumin (cat. no. V900933-100g; Sigma-Aldrich; Merck KGaA) and $22.52 \mathrm{mg} / \mathrm{ml}$ glycine in PBST $\left(\mathrm{PBS}+0.1 \%\right.$ Tween 20 ) for $30 \mathrm{~min}$ at $37^{\circ} \mathrm{C}$ to prevent non-specific binding of the antibodies. The cells were incubated with primary antibodies (diluted to $1: 200$ in 1\% BSA in PBST) against LC3B (cat. no. 18725-1-AP; ProteinTech Group, Inc.) in a humidified incubator at $37^{\circ} \mathrm{C}$ for $1 \mathrm{~h}$. After washing three times in PBS at 5 min for each wash, the cells were incubated for $1 \mathrm{~h}$ at $37^{\circ} \mathrm{C}$ in the dark with a fluorescein-conjugated secondary $\operatorname{IgG}$ antibody (1:200 in 1\% BSA in PBS; Thermo Fisher Scientific, Inc.). After washing three times with PBS for $5 \mathrm{~min}$ each in the dark, the cells were incubated with $0.1-1 \mu \mathrm{g} / \mathrm{ml}$ DAPI at rom temperature for $1 \mathrm{~min}$, washed with PBS and mounted with coverslips using a fluorescent mounting medium. The coverslip was sealed with nail polish to prevent drying and movement under the microscope. The slides were stored in the dark at -20 or $4^{\circ} \mathrm{C}$. The slides were imaged using a Zeiss Axiovert-200 inverted fluorescence microscope (Carl Zeiss AG; magnification, $\mathrm{x} 400$ ). ImageJ software (version 1.8.0; National Institutes of Health) was used to analyse the immunofluorescence density (IFD). The formula used was as follows: $I F D=($ the fluorescence intensity of the region of interest/the area of the region of interest).

ELISA. A total of 50-100 $\mu 1$ of the prepared standard and samples of JEG-3 cells supernatant were added to an antibody-coated 96-well microplate [human interleukin $1 \beta$ (IL-1 $\beta$ ) ELISA kit; cat. no. CSB-E08053h; human interferon $\gamma$ (IFN $\gamma)$ ELISA kit; cat. no. CSB-E04577h; and human tumor necrosis factor $\alpha$ (TNF $\alpha$ ) ELISA kit; cat. no. CSB-E04740h; all from CusaBio] The plate was covered and incubated at room temperature for $2 \mathrm{~h}$, and the solution was thoroughly decanted from the wells. The wells were washed with TBST four times using a squirt wash bottle or an automated 96-well plate washer. Next, $100 \mu 1$ of diluted detection antibodies was added to the wells, and the plate was covered and incubated at room temperature for $1 \mathrm{~h}$, after which the solution was thoroughly aspirated from the wells. After washing the wells four times, $100 \mu \mathrm{l}$ of diluted HRP conjugate was added to each well and the plate was covered and incubated at room temperature for $30 \mathrm{~min}$, after which the solution was thoroughly aspirated from the wells. After washing the wells with TBST four times, $100 \mu \mathrm{l}$ of the chromogenic substrate TMB was added to each well, and the plate was then developed at room temperature in the dark for $30 \mathrm{~min}$. Next, $100 \mu \mathrm{l}$ of stop solution was added to each well, and then the solution in the wells changed from blue to yellow. 
A

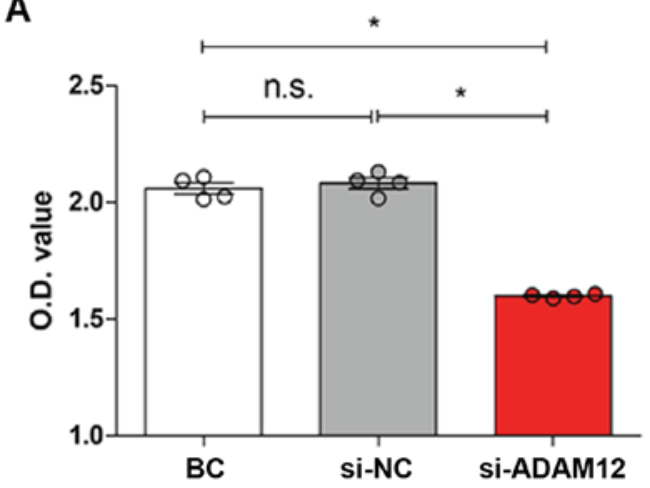

C

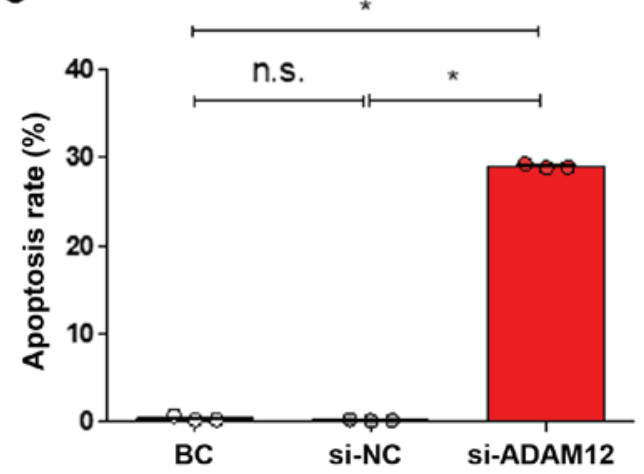

B

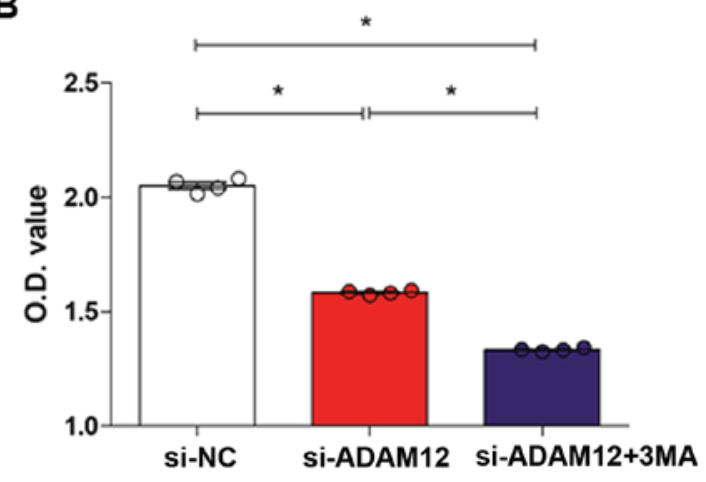

D

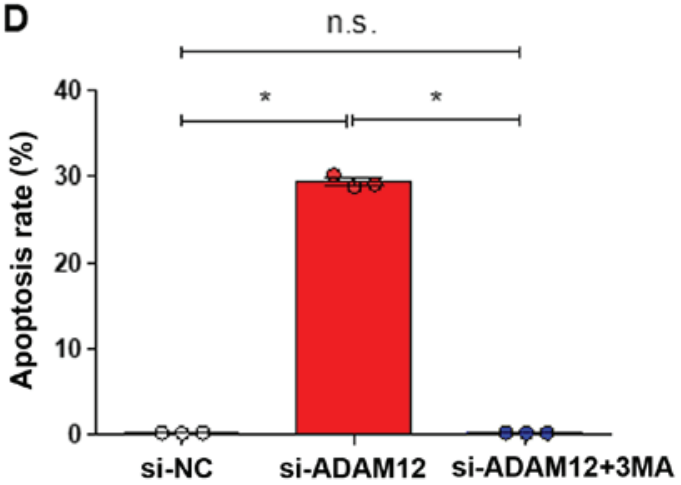

Figure 2. JEG-3 cell proliferation and apoptosis after ADAM12 silencing. (A) The CCK-8 assay showed that cell proliferation in the si-ADAM12 group was decreased compared with the BC and si-NC groups. (B) The CCK-8 assay showed that cell proliferation in the si-ADAM12 + 3MA group was slightly decreased compared with the si-ADAM12 group. (C) Flow cytometry showed that the apoptosis rate was increased in the si-ADAM12 group compared with the blank control and si-NC groups. (D) Flow cytometry test showed that the apoptosis rate was decreased in the si-ADAM12 + 3MA group compared with the si-ADAM12 group. " $\mathrm{P}<0.05$, as indicated. ADAM12, ADAM metallopeptidase domain 12; CCK-8, Cell Counting Kit-8; siRNA, small interfering RNA; BC, blank control; NC, negative control; 3MA, 3-methyladenine; OD, optical density; n.s., not significant.

The plate was evaluated within 30 min of stopping the reaction. The absorbance of each well was read at 450 and $550 \mathrm{~nm}$ with a microplate reader, and the $550 \mathrm{~nm}$ values were subtracted from the $450 \mathrm{~nm}$ values to correct for optical imperfections in the microplate. MasterPlex ReaderFit curve-fitting statistical software (version 2.0; Emerald Biotech Co., Ltd.) was used to plot a four-parameter logistic curve fit to the standards, and then the results for the test samples were calculated.

Statistical analysis. Data are presented as the means \pm standard error of the mean of at least three independent experiments. Differences among experimental groups were statistically analysed by SPSS software (version 17.0; SPSS, Inc.) using the analysis of variance followed by the least significant difference or Dunnett's post hoc tests, as applicable. $\mathrm{P}<0.05$ was considered to indicate a statistically significant difference.

\section{Results}

Transfection and ADAM12 silencing in JEG-3 cells. In the present study, untransfected JEG3 cells were observed using an optical microscope (magnification, x200; Fig. 1A). JEG-3 cells were transfected with three different targets of ADAM12-siRNA or scrambled-siRNA. Western blotting revealed that at $48 \mathrm{~h}$ post-transfection, ADAM12 expression was decreased in cells transfected with ADAM12-siRNA (target 1 and 3 ) but not in cells transfected with the si-NC) or ADAM12-siRNA target 2, compared with the BC cells. ADAM12-siRNA target 3 exhibited the best transfection efficiency compared with the other two targets $(\mathrm{P}<0.05$; Fig. 1B and C). Therefore, this siRNA was selected for subsequent experimentation.

ADAM12 silencing decreases cell proliferation and increases apoptosis in JEG-3 cells. The CCK-8 assay showed that cell proliferation was significantly decreased in the si-ADAM12 group compared with the si-NC group ( $\mathrm{P}<0.05$; Fig. $2 \mathrm{~A})$. Additionally, flow cytometry analysis revealed that the rate of apoptosis in the si-ADAM12 group was significantly increased compared with the si-NC group ( $\mathrm{P}<0.05$; Figs. $2 \mathrm{C}$ and $\mathrm{S} 1 \mathrm{~A})$. Together, these findings confirmed that cell apoptosis was increased after ADAM12 silencing.

The levels of apoptosis-associated proteins were measured by western blotting following ADAM12-siRNA transfection (Fig. 3A). The results revealed that the levels of caspase-3 (Fig. 3G-I) and caspase-9 were not changed ( $\mathrm{P}>0.05$; Fig. 3J-L), but the levels of Bax and p53 levels were significantly increased in the si-ADAM12 group compared with the si-NC group (Fig. 3C and E; $\mathrm{P}<0.05$ ).

ADAM12 silencing increases autophagy in JEG-3 cells. The expression levels of the autophagy-associated proteins LC3B 
A

BC Si-NC Si-ADAM12

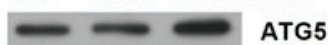

$\because+\cdots$ BAX

$\omega$ Pro-caspase-3

- - C cleaved caspase-3

$=\infty$ Pro-caspase-9

- $=$ cleaved caspase-9

$= \pm \equiv{ }_{\text {LC3B }}$

- -

$\omega$ Actin

C

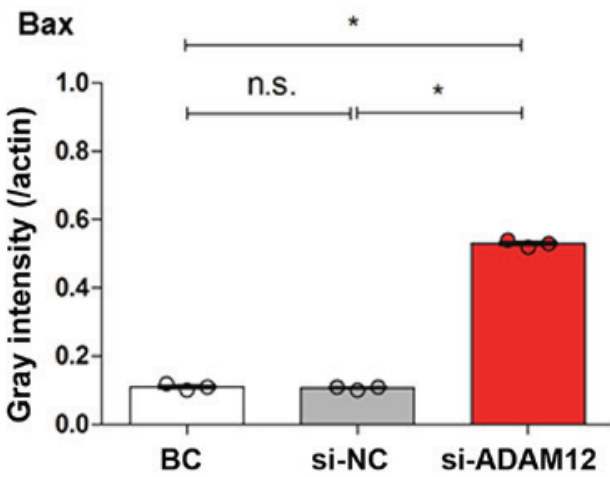

E

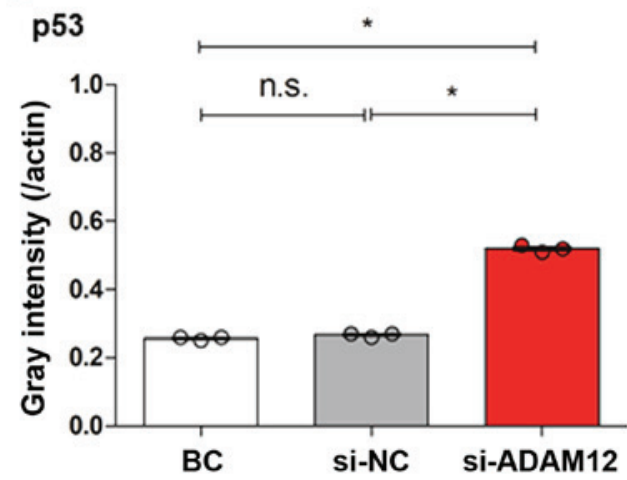

B

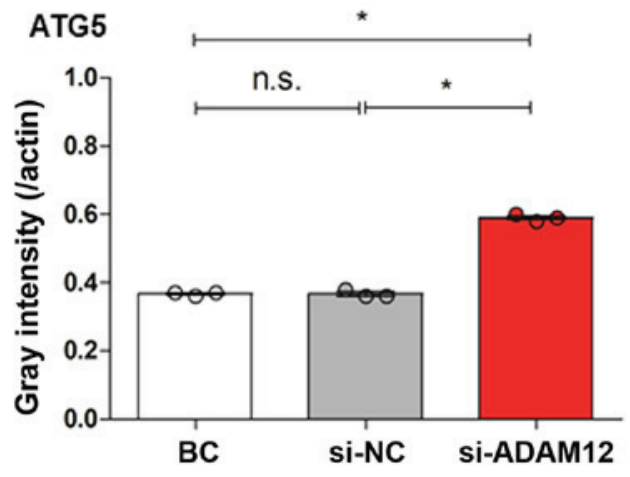

D

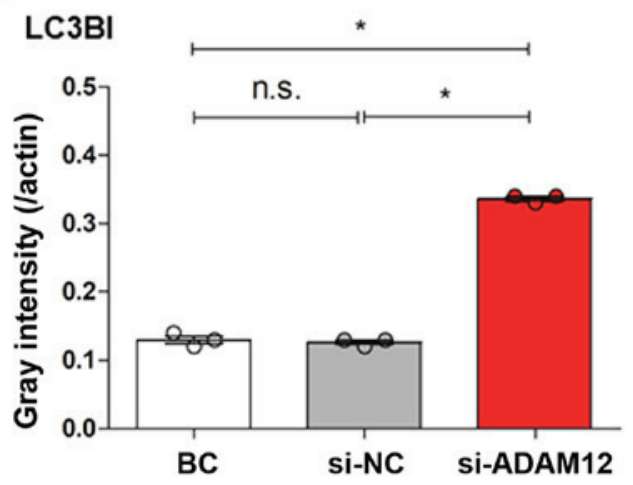

$\mathbf{F}$

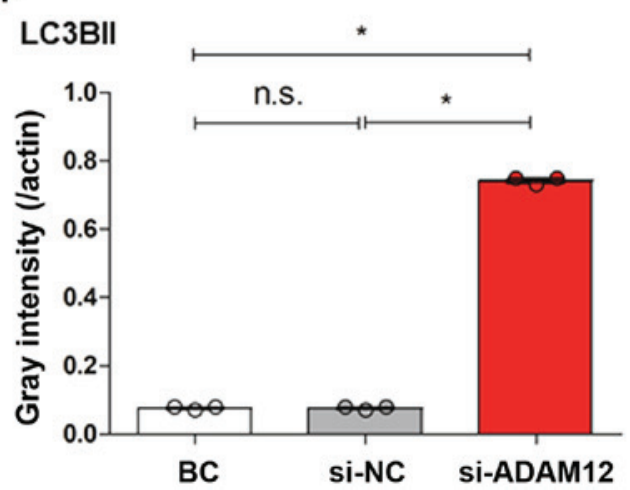

Figure 3. Western blotting was used to investigate the expression levels of apoptosis- and autophagy-assciacted proteins after ADAM12 silencing in JEG-3 cells. (A) Western blotting bands of autophagy-associated proteins (ATG5 and LC3B) and apoptosis-associated proteins (caspase 3, caspase 9, Bax and p53) in the BC, si-NC and si-ADAM12 groups. (B) Quantification of western blotting showed that the level of ATG5 expression was increased in the si-ADAM12 group compared with the BC and si-NC groups. (C) Quantification of western blotting showed that the level of Bax expression was increased in the si-ADAM12 group compared with the BC and si-NC groups. (D) Quantification of western blotting showed that the level of LC3BI expression was increased in the si-ADAM12 group compared with the BC and si-NC groups. (E) Quantification of western blotting showed that the level of p53 expression was increased in the si-ADAM12 group compared with the BC and si-NC groups. (F) Quantification of western blotting showed that the level of LC3BII expression was increased in the si-ADAM12 group compared with the BC and si-NC groups.

and ATG5 in JEG-3 cells were detected by western blotting after ADAM12 silencing. The results showed that the levels of LC3BI and LC3BII in the si-ADAM12 cells were higher than those in the control cells $(\mathrm{P}<0.05$; Fig. 3D and $\mathrm{F})$. Furthermore, the level of ATG5 expression was increased in si-ADAM12 cells compared with the si-NC cells $(\mathrm{P}<0.05$; Fig. 3B).

In addition, the expression of the autophagy protein LC3B was investigated using immunofluorescence analysis. The IFD of LC3B in the si-ADAM12 group was significantly increased compared with the $\mathrm{BC}$ and si-NC groups $(\mathrm{P}<0.05$; Fig. 4A and B).

Autophagy mediates the effect of ADAM12 silencing on cell proliferation and apoptosis in JEG-3 cells. To investigate whether cell apoptosis was mediated by autophagy in JEG-3 cells after ADAM12 silencing, the ADAM12-siRNA transfected JEG-3 cells were treated with an autophagy inhibitor 3-methyladenine (3MA). The cell cycle of the 3MA-treated JEG-3 cells after ADAM12 silencing was analyzed 

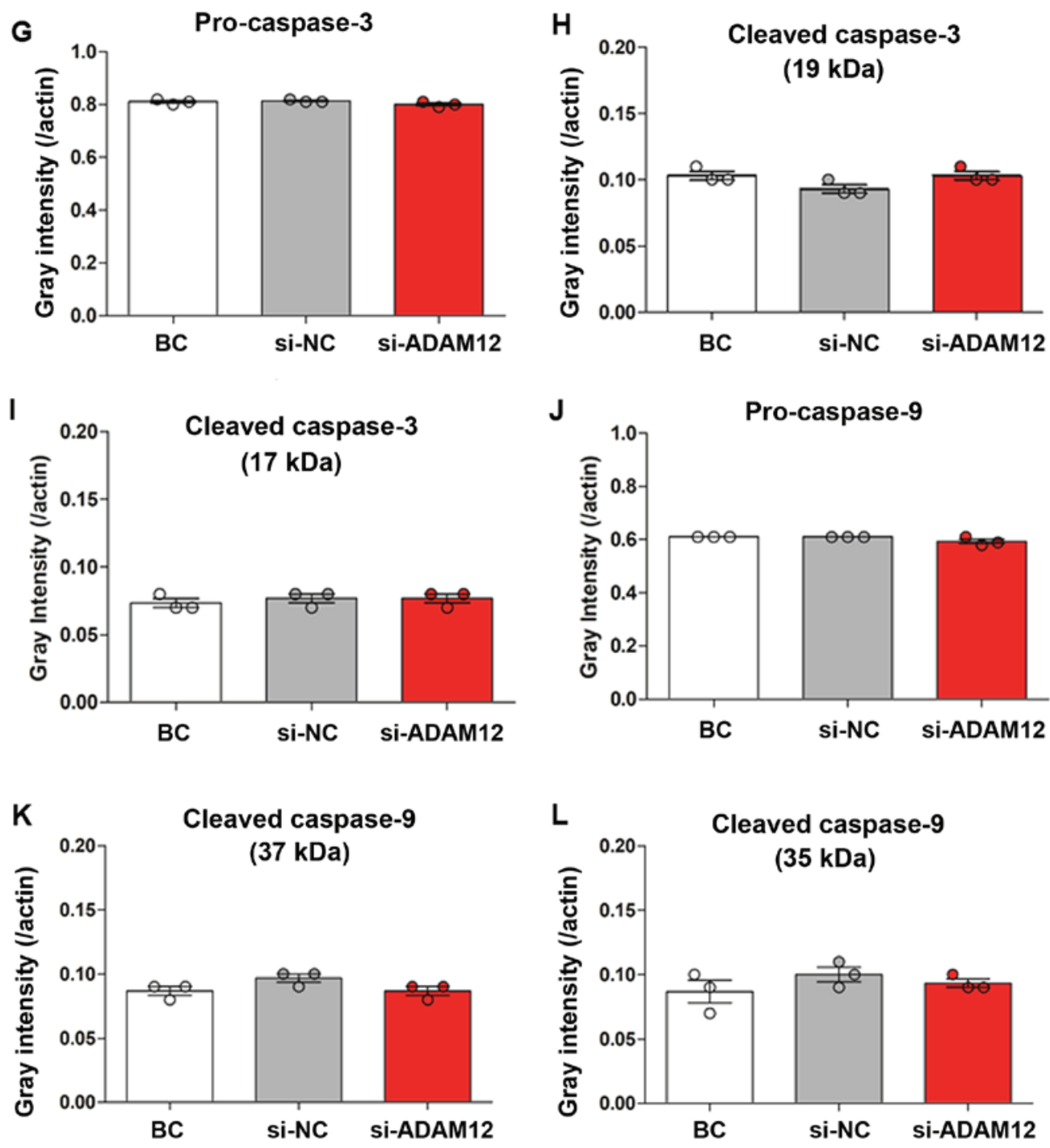

Figure 3. Continued. Western blotting was used to investigate the expression levels of apoptosis- and autophagy-assciacted proteins after ADAM12 silencing in JEG-3 cells. Quantification of western blotting showed that the level of (G) procaspase 3, (H) cleaved caspase 3 (19 kDa) and (I) cleaved caspase 3 (17 kDa) expression in the si-ADAM12 groups was similar to the BC and si-NC groups. Quantification of western blotting showed that the level of (J) procaspase 9 , (K) cleaved caspase $9(37 \mathrm{kDa})$ and $(\mathrm{L})$ cleaved caspase $9(35 \mathrm{kDa})$ in the si-ADAM12 group was similar to the $\mathrm{BC}$ and si-NC groups. ${ }^{*} \mathrm{P}<0.05$, as indicated. ADAM12, ADAM metallopeptidase domain 12; ATG5, autophagy related 5; LC3B, microtubule-associated protein-light-chain 3; BC, blank control; si, small interfering; NC, negative control; n.s., not significant.

(Figs. 5 and S2), and the results showed that the number of cells in the si-ADAM12 group was reduced in the $\mathrm{S}$ and $\mathrm{G} 2$ phases $(\mathrm{P}<0.05$; Fig. 5C-E) but increased in the G1 phase, compared with the si-NC group ( $\mathrm{P}>0.05$; Fig. 5B). However, no differences were observed in all the cell cycle phases (G1, S and G2) between the si-ADAM12 + 3MA and si-ADAM12 groups ( $\mathrm{P}>0.05$; Fig. 5B-E).

The CCK-8 assay showed that the cell proliferation in the si-ADAMA12 + 3MA group was decreased compared with the of si-ADAM12 and si-NC groups (Fig. 2B). Flow cytometry was to analyse the apoptosis rate and demonstrated that the rate of apoptosis in the si-ADAM12 group was significantly increased $(\mathrm{P}<0.05$; Figs. $2 \mathrm{C}, \mathrm{D}$ and $\mathrm{S} 1 \mathrm{~A})$ compared with the $\mathrm{BC}$ and si-NC groups. The apoptosis rate was significantly decreased in the si-ADAM12 + 3MA group compared with the si-ADAM12 group ( $\mathrm{P}<0.05$; Figs. $2 \mathrm{D}$ and $\mathrm{S} 1 \mathrm{~B})$. Moreover, the western blotting data showed that the levels of the apoptotic proteins p53 and Bax were significantly decreased in the si-ADAM12 + 3MA group compared with the si-ADAM12 group $(\mathrm{P}<0.05$; Fig. $6 \mathrm{C}$ and $\mathrm{E})$. Additionally, the levels of Bcl-2 were significantly decreased in the si-ADAM12 $(\mathrm{P}<0.05)$ but partly rescued in si-ADAM + 3MA group, compared with the si-NC group $(\mathrm{P}<0.05$; Fig. $6 \mathrm{I})$. The levels of the autophagy-associate proteins LC3BI and LC3BII were decreased in the si-ADAM12 + 3MA group compared with the si-ADAM12 group $(\mathrm{P}<0.05 ;$ Fig. $6 \mathrm{G}$ and $\mathrm{H})$. In addition, the IFD of LC3B in the si-ADAM12 + 3MA group was consistent with that of the si-NC $(\mathrm{P}>0.05)$, but the IFD in the si-ADAM12 $+3 \mathrm{MA}$ group was significantly decreased compared with the si-ADAM12 group $(\mathrm{P}<0.05$; Fig. $4 \mathrm{~B}$ and $\mathrm{D})$. Together, the findings confirmed that the pro-apoptotic effect of ADAM12 silencing was blocked after the inhibition of autophagy in JEG-3 cells.

ADAM12 silencing decreases the inflammatory response in JEG-3 cells. ELISA results showed that IL-1 $\beta$ (Fig. 7A), 
A $B C$
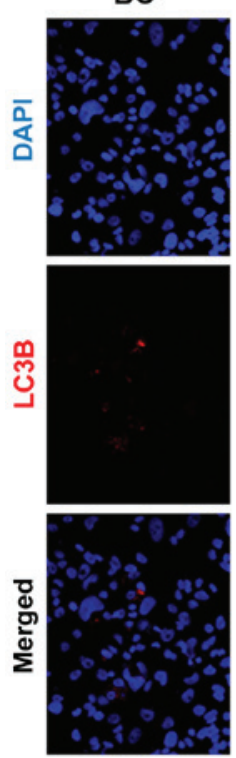

C
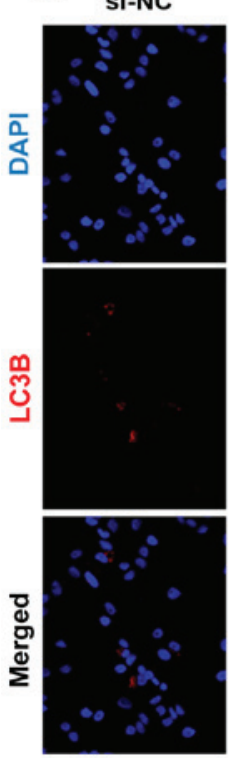

si-NC
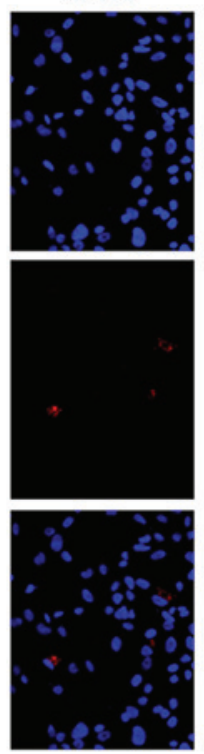

si-ADAM12
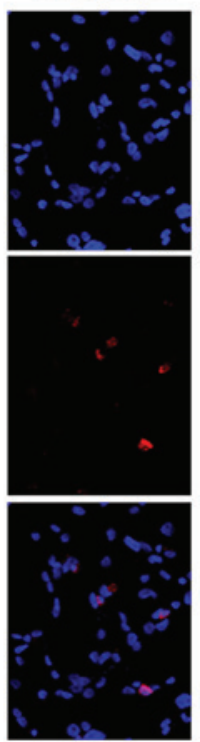

Si-ADAM12
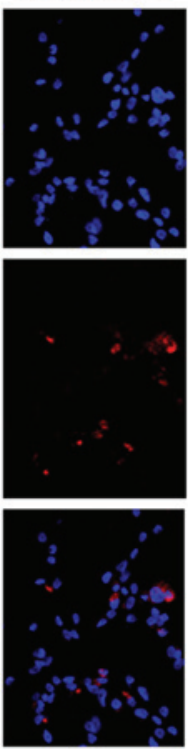

si-ADAM12+3MA
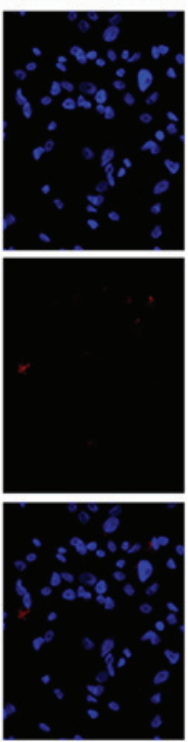

B

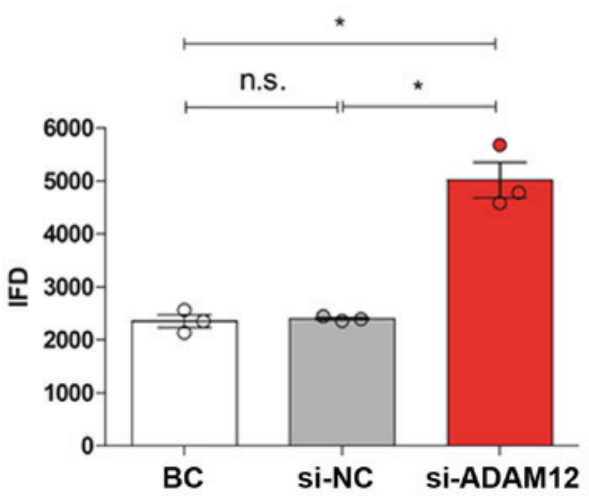

D

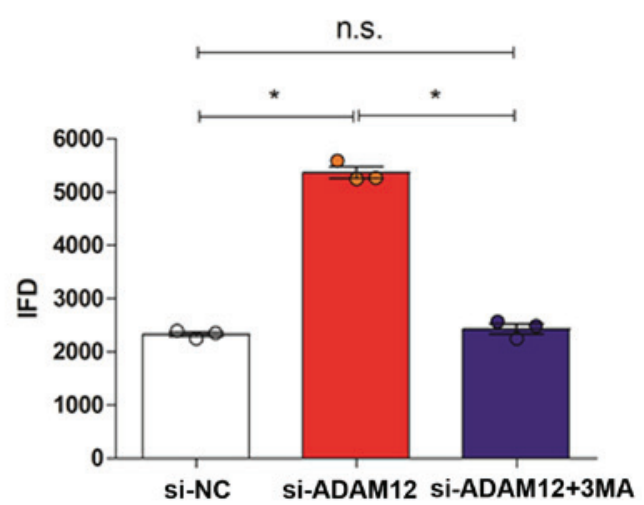

Figure 4. Immunofluorescence staining of the autophagy-associated protein LC3B in JEG-3 cells after ADAM12 silencing. (A) Images of immunofluorescence staining (magnification, $x 400$ ). (B) Quantification of immunofluorescence showed that the IFD of LC3B was increased in the si-ADAM12 group compared with the BC and si-NC groups. (C) Images of immunofluorescence staining (magnification, $\mathrm{x} 400$ ). (D) Quantification of immunofluorescence showed that the IFD of LC3B was decreased in the si-ADAM12 + 3MA group compared with the si-ADAM12 group, but similar to the si-NC group. "P<0.05, as indicated. LC3B, microtubule-associated protein-light-chain 3; ADAM12, ADAM metallopeptidase domain 12; IFD, immunofluorescence density; si, small interfering; 3MA, 3-methyladenine; NC, negative control; BC, blank control; n.s., not significant.

IFN- $\gamma$ (Fig. 7B) and TNF- $\alpha$ (Fig. 7C) levels were significantly reduced in the si-ADAM12 group compared with the BC and si-NC groups $(\mathrm{P}<0.05)$.

Autophagy fails to impact the effect of ADAM12 silencing on the inflammatory response in JEG-3 cells. IL-1 $\beta$ (Fig. 7D), IFN- $\gamma$ (Fig. 7E) and TNF- $\alpha$ (Fig. 7F) were significantly reduced in the si-ADAM12 + 3MA group compared with the si-NC group $(\mathrm{P}<0.05)$, while IL-1 $\beta$ (Fig. 7D) and TNF- $\alpha$ concentrations (Fig. 7F) exhibited little difference between the si-ADAM12 + 3MA and si-ADAM12 groups ( $P>0.05)$. In addition, the level of IFN- $\gamma$ was significantly decreased in the
si-ADAM12 + 3MA group compared with the si-ADAM12 group $(\mathrm{P}<0.05$; Fig. 7E).

$N F-\kappa B$ and $m T O R$ signalling. To investigate the potential mechanism by which ADAM12 silencing-mediated apoptosis in human choriocarcinoma cells, the levels of p65-NF- $\mathrm{kB}(\mathrm{p} 65$; Fig. 6A and B), mTOR, and p-mTOR were measured in JEG-3 cells (Fig. 6A and F). ADAM12 silencing significantly reduced p65 expression in the si-ADAM12 group compared with the si-NC group $(\mathrm{P}<0.05 ;$ Fig. $6 \mathrm{~B})$, but the level of $\mathrm{p} 65$ protein was similar in the si-ADAM12 + 3MA and si-ADAM12 groups ( $P>0.05$; Fig. 6B). Furthermore, mTOR expression levels did 
A

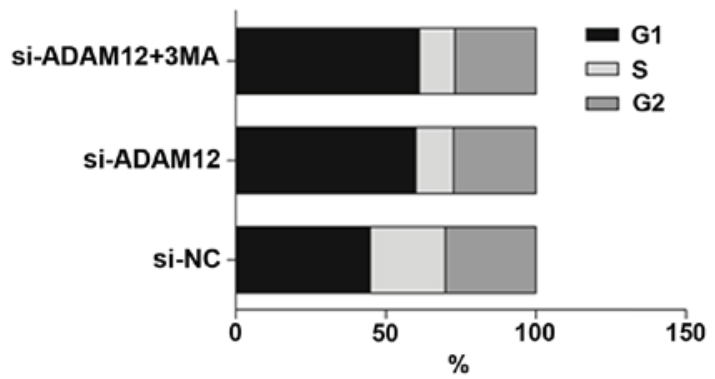

C

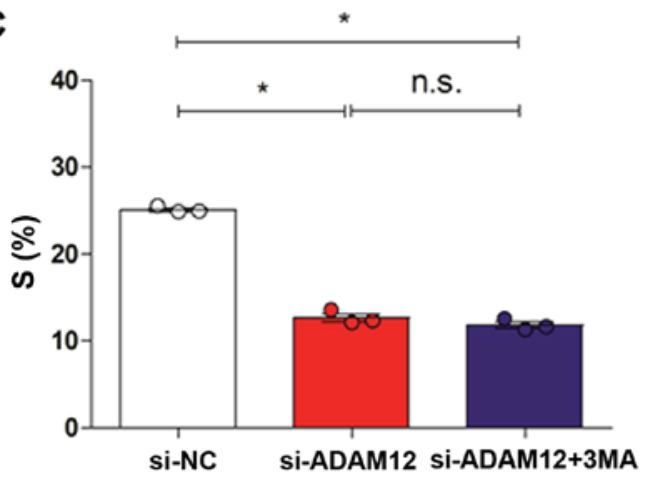

E

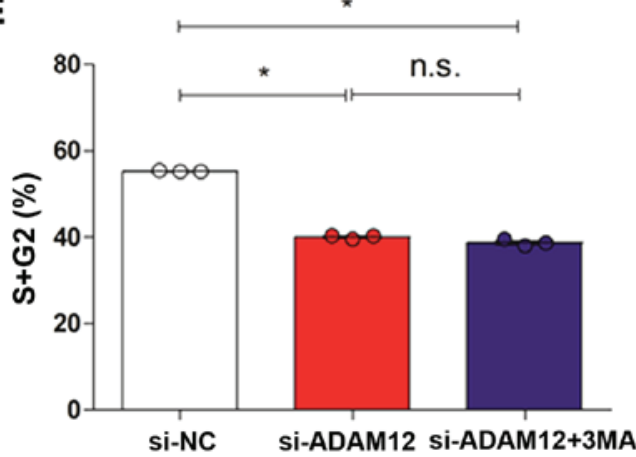

B

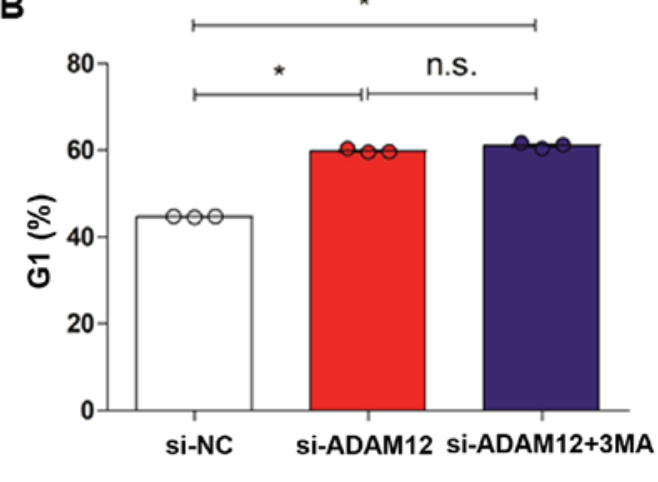

D

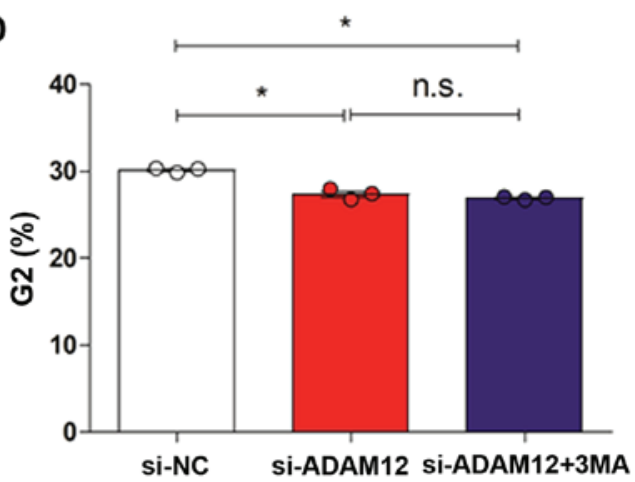

Figure 5. Cell cycle analysis of si-ADAM12 transfected JEG-3 cells after treatment with the autophagy inhibitor 3MA. (A) Column plot of cell cycle (G1, S and G2 phases) in JEG-3 cells in the si-NC, si-ADAM12 and si-ADAM12 + 3MA groups. (B) Quantification of the G1 phase showed that the percentage of cells in this phase was increased in the JEG-3 cells in the si-ADAM12 + 3MA group compared with the si-NC group, but was similar to the si-ADAM12 group. (C) Quantification of S phase showed that the percentage of cells in this stage was decreased in the JEG-3 cells in the si-ADAM12 + 3MA group compared with the si-NC group, but was similar to the si-ADAM12 group. (D) Quantification of the G2 phase showed that the percentage of cells in this phase was decreased in the JEG-3 cells in the si-ADAM12 + 3MA group compared with the si-NC group, but was similar to the si-ADAM12 group. (E) Quantification of the S and G2 phase showed that the percentage of cells in this S+G phase was decreased in JEG-3 cells in the si-ADAM12 + 3MA group compared with the si-NC group, but was similar to the si-ADAM12 group..P<0.05, as indicated. si, small interfering; ADAM12, ADAM metallopeptidase domain 12; 3MA, 3-methyladenine; NC, control; n.s., not significant.

not differ among the si-NC, si-ADAM12 and si-ADAM12 + 3MA groups (Fig. 6D), while p-mTOR expression was downregulated in the si-ADAM12-treated cells, compared with the si-ADAM12 + 3MA group, and this effect was significantly rescued in the si-ADAM12 + 3MA group $(\mathrm{P}<0.05$; Fig. $6 \mathrm{~F})$.

\section{Discussion}

The prognosis of choriocarcinoma is related to clinical stage and trophoblastic activity $(1,2)$. Treatment of choriocarcinoma may include chemotherapy radiation therapy or combination therapy $(29,30)$. Cancer-targeted therapies based on specific genes or functional proteins are receiving increasing attention $(31,32)$. ADAM12 is a metalloprotein with cell adhesion and hydrolytic activities and has been widely reported to mediate tumour cell proliferation (16) and apoptosis resitance (9). The present study focused on the effect of ADAM12 silencing on cell apoptosis and autophagy in choriocarcinoma cells. Multiple direct and indirect interactions have been described suggesting mechanistic overlap and interaction between the apoptosis machinery and autophagy proteins (23-25). Although it was originally identified as a cell survival mechanism, autophagy has highly context-specific effects in mediating cell death $(33,34)$. In specific contexts, 
A

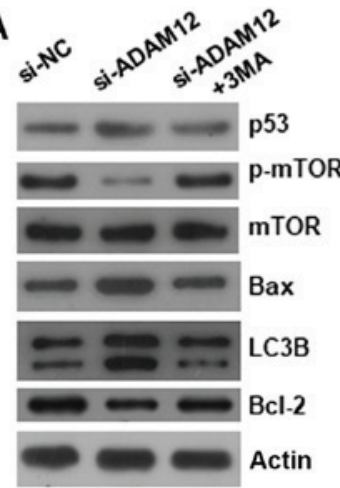

C

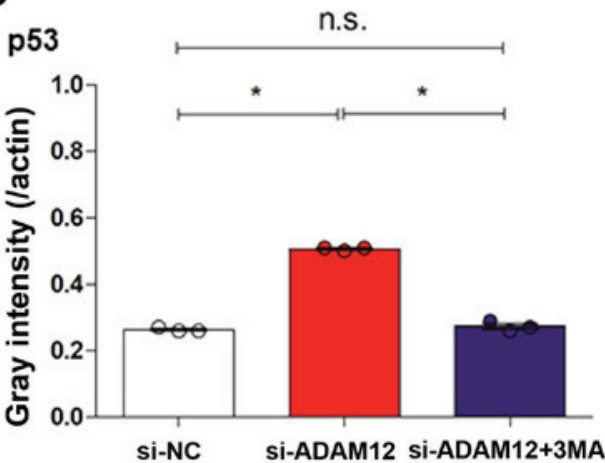

E

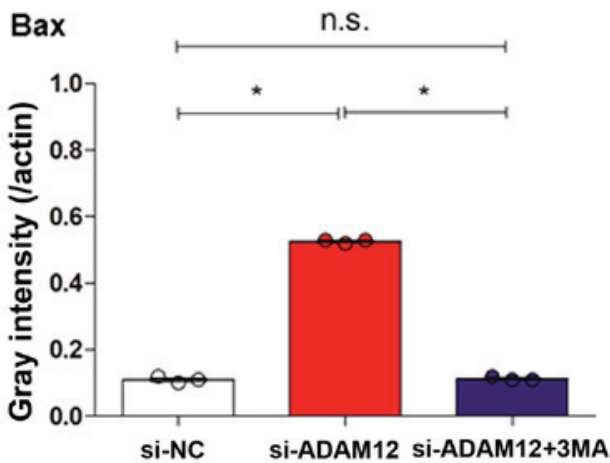

B

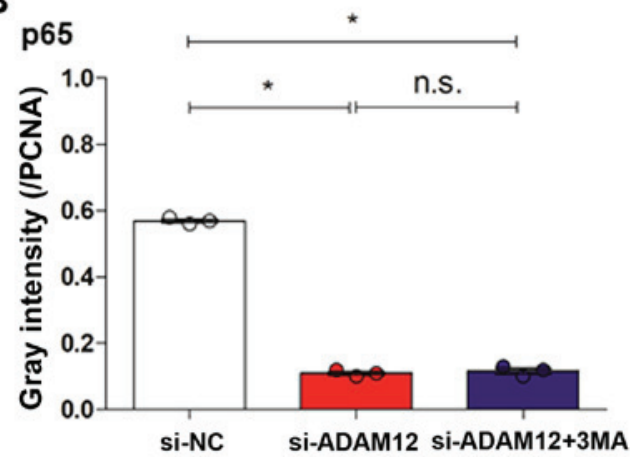

D

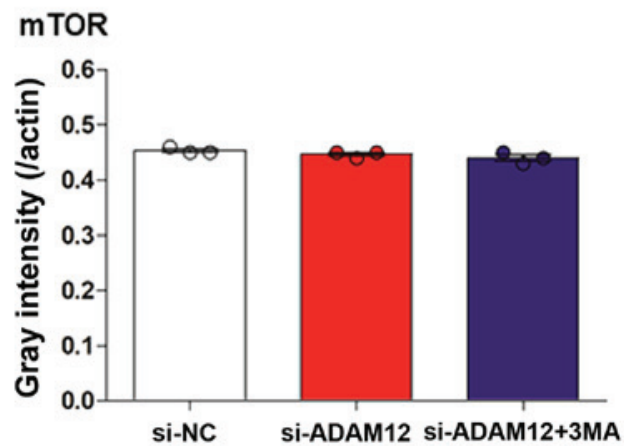

$\mathbf{F}$

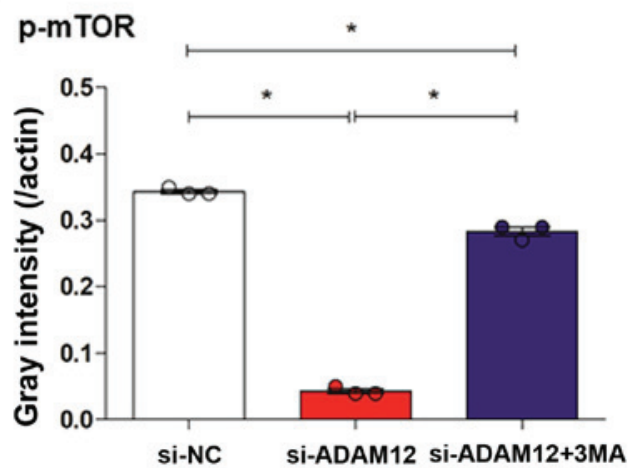

Figure 6. Western blotting was used to detect the expression levels of apoptosis- and autophagy-associated proteins, nuclear p65 and mTOR after $3 \mathrm{MA}$ treatment in si-ADAM12 transfected JEG-3 cells. (A) Western blotting bands of LC3B, Bax, p53, nuclear p65 and m-TOR in the si-NC, si-ADAM12 and si-ADAM12 + 3MA groups. (B) Quantification of western blotting showed that the level of nuclear p65 expression was decreased in the si-ADAM12 + 3MA group in compared with the si-NC group but was similar to the si-ADAM12 group. (C) Quantification of western blotting showed that the level of p53 expression was decreased in the si-ADAM12 + 3MA group compared with the si-ADAM12 group but was similar to the si-NC group. (D) Quantification of western blotting showed that the level of mTOR expression in the si-ADAM12 + 3MA group was similar to the si-ADAM12 and si-NC groups. (E) Quantification of western blotting showed that the level of Bax expression was decreased in the si-ADAM12 + 3MA group compared with the si-ADAM12 group but similar to the si-NC group. (F) Quantification of western blotting showed that the level of p-mTOR expression was increased in the si-ADAM12 + 3MA group compared with the si-ADAM12 group but slightly decreased compared with the si-NC group.

cell death can also be led by autophagy (35-41). Studies in mammalian and other model systems show that autophagy can paradoxically have pro-apoptosis or pro-survival functions, depending on the context $(23,42,43)$. It has recently been shown that there are interplays between autophagy-dependent apoptosis and other types of cell death including apoptosis and necrosis (26).

The present study revealed that ADAM12 silencing promoted cell apoptosis by activating autophagy in human choriocarcinoma JEG-3 cells. Furthermore, ADAM12 silencing decreased cell proliferation and increased the rate of apoptosis. The levels of the apoptotic proteins Bax and p53 expression were upregulated by ADAM12 silencing in JEG-3 cells but cleaved caspase-3 levels were unchanged. Therefore, it was speculated that ADAM12 silencing-induced apoptosis may occur through a caspase-independent manner, as there are caspase-independent apoptotic pathways, such as the apoptosis-inducing factor-mediated pathway (44) and TNF receptor superfamily member 1A-mediated apoptosis (45).

It was reported that the levels and activity of the apoptotic proteins p53 and Bcl-2 can be regulated through diverse mechanisms (46-48). The present study showed that ADAM12 
G

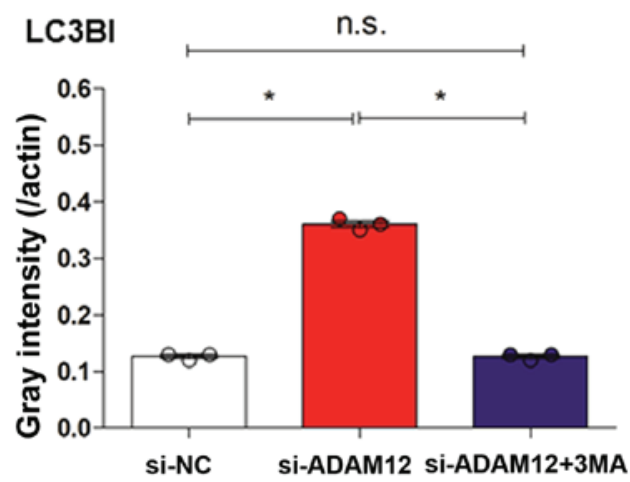

H

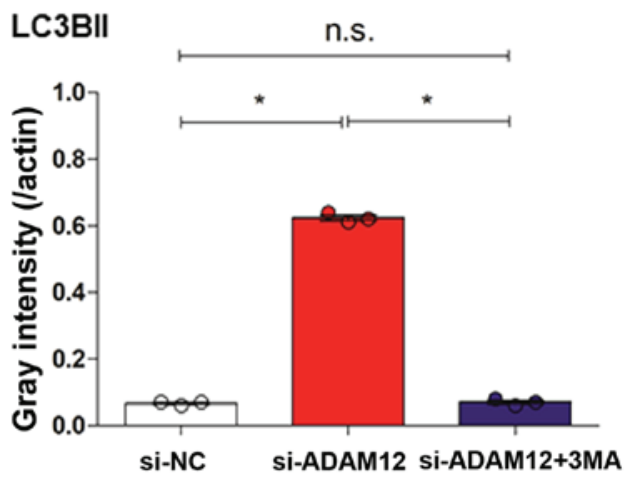

I

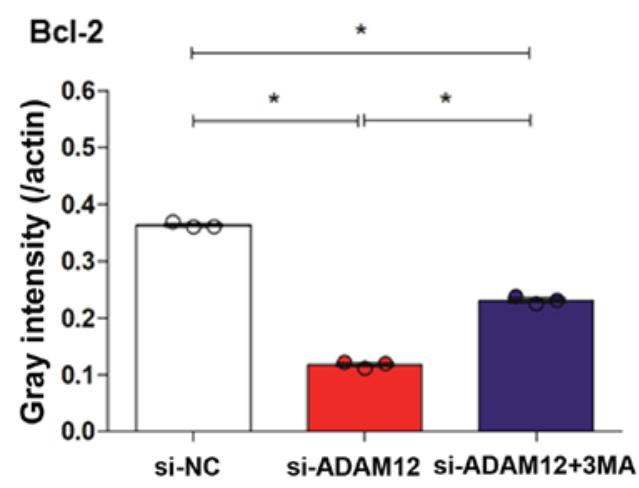

Figure 6. Continued. Western blotting was used to detect the expression levels of apoptosis- and autophagy-associated proteins, nuclear p65 and mTOR after 3MA treatment in si-ADAM12 transfected JEG-3 cells. (G) Quantification of western blotting showed that the level of LC3BI expression was decreased in the si-ADAM12 +3 MA group compared with si-ADAM12 group but was similar to the si-NC group. (H) Quantification of western blotting showed that the level of LC3BII expression was increased in the si-ADAM12 + 3MA group compared with the si-ADAM12 group but similar to the si-NC group. (I) Quantification of western blotting showed that the level of Bcl-2 expression was decreased in the si-ADAM12 group compared with the si-NC but partly rescued in the si-ADAM12 + 3MA group. "P<0.05, as indicated. 3MA, 3-methyladenine; si, small interfering; ADAM12, ADAM metallopeptidase domain 12; LC3B, microtubule-associated protein-light-chain 3; NC, negative control; PCNA, proliferating cell nuclear antigen; n.s., not significant.

silencing enhanced cell apoptosis but that after the inhibition of autophagy, the rate of cell apoptosis did not change, which suggested that autophagy indeed mediated the pro-apoptotic effect of ADAM12 silencing. The autophagy-related protein ATG5 is a key protein that is involved in the extension of the phagophore membrane in autophagy vesicles and forms a complex with autophagy related 12 and autophagy related 16 like 1 (49). These complexes are required for the conjugation of LC3-I to phosphatidylethanolamine to form LC3-II (50-54). Accordingly, the present study provided evidence for the upregulation of autophagy by ADAM12 silencing by detecting autophagy markers, such as ATG5, LC3I and LC3II proteins. The results showed that ADAM12 silencing upregulated the expression levels of these autophagy proteins in JEG-3 cells.

In the cellular network of signal integration, autophagy and immunomodulation are interdependent (53-56). Autophagy is involved in the induction and suppression of inflammation and vice versa $(55,57,58)$. The proinflammatory cytokine TNF $\alpha$ has been shown to stimulate autophagy, and autophagy also contributes to the secretion of this cytokine (59-61). However, autophagy is regulated in its response to inflammation, such as participating in the regulation of inflammasome activation (62) and the clearance of protein complexes, such as inflammasomes, through proteasomal degradation (63). In the present study, ADAM12 silencing not only increased autophagy but also exerted an anti-inflammatory effect in JEG-3 cells, but this anti-inflammatory effect of ADAM12 silencing was not blocked when autophagy was inhibited in JEG-3 cells. At the molecular level, autophagy plays a context-dependent pro-survival or pro-death role by regulating different signalling pathways, such as p53, Bcl-2, and mTOR in cancer $(23,42,43,64)$. The p53 gene is one of the target genes of the transcription factor $\mathrm{NF}-\mathrm{\kappa B}(65)$, and the $\mathrm{Bcl}-2$ gene is transcriptionally regulated by $\mathrm{NF}-\kappa \mathrm{B}$ and directly links the TNF- $\alpha / N F-\kappa B$ signalling pathways $(66,67)$. NF- $\kappa \mathrm{B}$ targets inflammation not only directly by increasing the production of inflammatory cytokines, chemokines and adhesion molecules, but it also regulates cell proliferation, apoptosis, morphogenesis and differentiation (68-70). In the present study, ADAM12 silencing reduced the expression level of nuclear p65-NF- $\kappa$ B in JEG-3 cells. However, ADAM12 silencing did not change the expression level of p65-NF- $\mathrm{B}$ in JEG-3 cells, even after autophagy was inhibited.

mTOR is a serine/threonine protein kinase and a key factor serving as the convergence point for several upstream stimuli and pathways to regulate cell growth, cell proliferation, cell motility, cell survival, protein synthesis, translation and autophagy (71-76). Growth factors, glucose and amino acids also activate mTOR and suppress autophagy, whereas nutrient deprivation will suppress mTOR, leading to the 

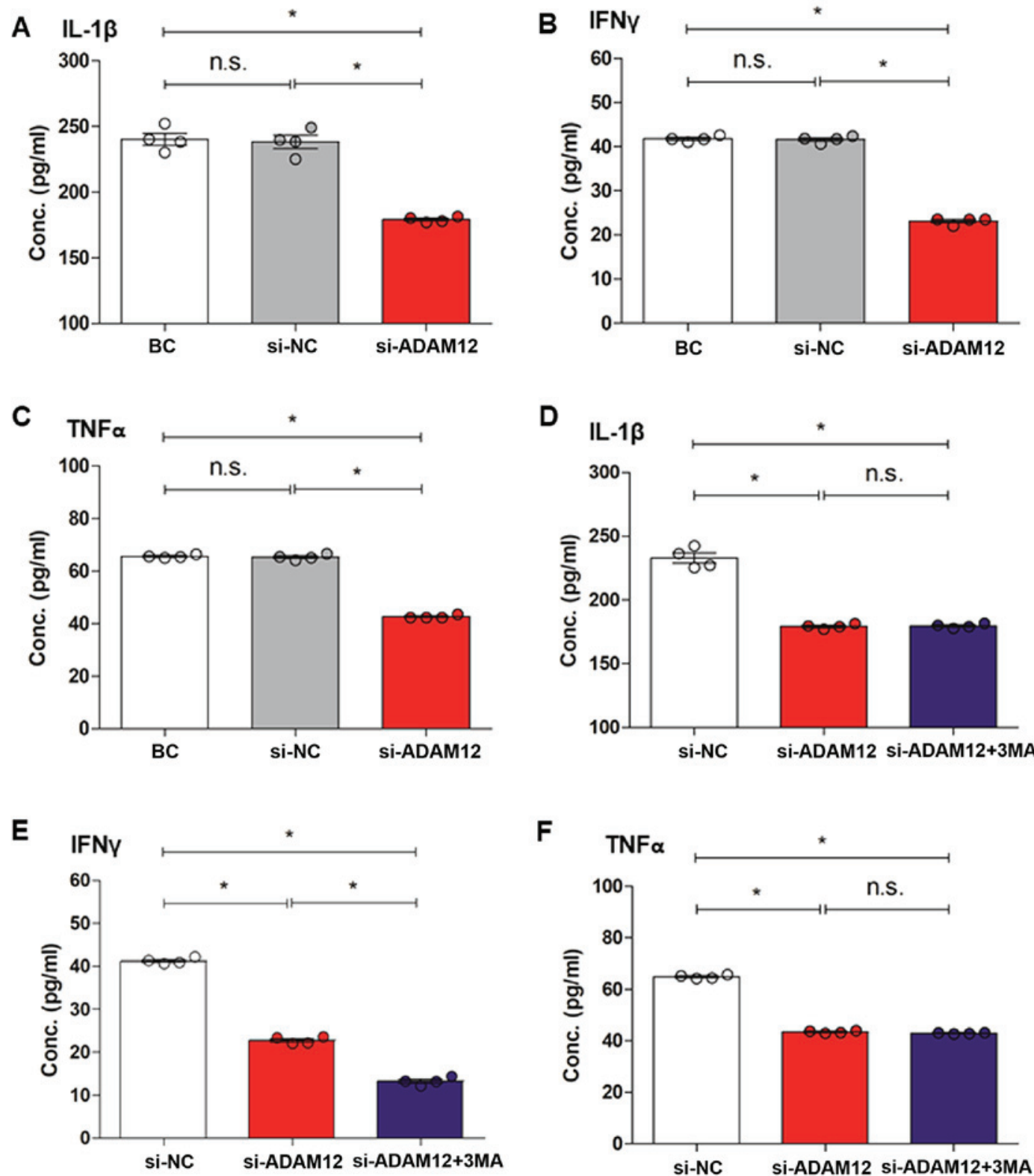

Figure 7. ELISA assay for the expression levels of inflammatory factors after ADAM12 silencing in JEG-3 cells. (A) Quantification of ELISA showed that the level of IL-1 $\beta$ expression was decreased in the si-ADAM12 group compared with the BC and si-NC groups. (B) Quantification of ELISA showed that the level of IFN $\gamma$ expression was decreased in the si-ADAM12 group compared with the BC and si-NC groups. (C) Quantification of ELISA showed that the level of TNF $\alpha$ expression was decreased in the si-ADAM12 group compared with the BC and si-NC groups. (D) Quantification of ELISA showed that the level of IL-1 $\beta$ expression was decreased in the si-ADAM12 + 3MA group compared with si-NC group, but was similar to the si-ADAM12 group. (E) Quantification of ELISA showed that the level of IFN $\gamma$ expression was greatly decreased in the si-ADAM12 + 3MA group compared with the si-NC group and slightly decreased compared with the si-ADAM12 group. (F) Quantification of ELISA showed that the level of TNF $\alpha$ expression was decreased in the si-ADAM12 + 3MA group compared with the si-NC group but was similar to the si-ADAM12 group. " $\mathrm{P}<0.05$, as indicated. ADAM12, ADAM metallopeptidase domain 12; IL-1 $\beta$, interleukin-1 $\beta$; BC, blank control; si, small interfering; NC, negative control; IFN $\gamma$, interferon $\gamma$; 3MA, 3-methyladenine; TNF $\alpha$, tumour necrosis $\alpha$; n.s., not significant.

activation of autophagy (77-80). mTOR and autophagy are closely associated, and defects in signalling through either pathway are known to drive the onset of a range of human diseases, such as cancer and neurodegenerative diseases (80-82). In the present study, ADAM12 silencing increased the expression level of autophagy proteins in JEG-3 cells and significantly reduced the level of phosphorylated mTOR in JEG-3 cells, which is responsible for the activation of the mTOR signalling pathway. However, the downregulation of phosphorylated-mTOR expression was rescued after the suppression of autophagy in JEG-3 cells, and the pro-apoptotic effect of ADAM12 silencing was blocked after the suppression of autophagy. These data confirmed that i) there might be a relationship between the impeded nuclear enrichment of p65-NF- $\mathrm{KB}$ by ADAM12 silencing and the anti-inflammatory process of ADAM12 silencing; and ii) ADAM12 silencing activated autophagy via the regulation of the mTOR signalling pathway.

The present study only investigated one choriocarcinoma cell line, and further studies are warranted to assess other choriocarcinoma cell lines and to validate the results obtained. In conclusion, the present study revealed that ADAM12 may 
serve as a potential anticancer agent due to its effects on proliferation and apoptosis of choriocarcinoma cells.

\section{Acknowledgements}

Not applicable.

\section{Funding}

The present study was supported by the Hunan Provincial Natural Science Foundation of China (grant no. 2016JJ2169).

\section{Availability of data and materials}

The datasets used and/or analyzed during the current study are available from the corresponding author on reasonable request.

\section{Authors' contributions}

ZHT designed the experiments. LW, ZHT, YZ, NKK, HNL and $\mathrm{YZ}$ performed the experiments and analyzed the data. LW and ZHT wrote the manuscript. All authors read and approved the final manuscript.

\section{Ethics approval and consent to participate}

Not applicable.

\section{Patient consent for publication}

Not applicable.

\section{Competing interests}

The authors declare that they have no competing interests.

\section{References}

1. Wreczycka-Cegielny P, Cegielny T, Oplawski M, Sawicki W and Kojs ZC: Current treatment options for advanced choriocarcinoma on the basis of own case and review of the literature. Ginekol Pol 89: 711-715, 2018.

2. Cheung AN, Zhang HJ, Xue WC and Siu MK: Pathogenesis of choriocarcinoma: Clinical, genetic and stem cell perspectives. Future Oncol 5: 217-231, 2009.

3. Wells M: The pathology of gestational trophoblastic disease: Recent advances. Pathology 39: 88-96, 2007.

4. Becherer JD and Blobel CP: Biochemical properties and functions of membrane-anchored metallprotease-disintegrin proteins (ADAMs). Curr Top Dev Biol 54: 101-123, 2003.

5. Klein T and Bischoff R: Active metalloproteases of the A disintegrin and metalloprotease (ADAM) family: Biological function and structure. J Proteome Res 10: 17-33, 2011.

6. Roy R, Wewer UM, Zurakowski D, Pories SE and Moses MA ADAM 12 cleaves extracellular matrix proteins and correlates with cancer status and stage. J Biol Chem 279: 51323-51330, 2004.

7. Fröhlich C, Nehammer C, Albrechtsen R, Kronqvist $\mathrm{P}$, Kveiborg M, Sehara-Fujisawa A, Mercurio AM and Wewer UM: ADAM12 produced by tumor cells rather than stromal cells accelerates breast tumor progression. Mol Cancer Res 9: 1449-1461, 2011.

8. Roy R, Rodig S, Bielenberg D, Zurakowski D and Moses MA ADAM12 transmembrane and secreted isoforms promote breast tumor growth: A distinct role for ADAM12-S protein in tumor metastasis. J Biol Chem 286: 20758-20768, 2011.
9. Kveiborg M, Fröhlich C, Albrechtsen R, Tischler V, Dietrich N, Holck P, Kronqvist P, Rank F, Mercurio AM and Wewer UM: A role for ADAM12 in breast tumor progression and stromal cell apoptosis. Cancer Res 65: 4754-4761, 2005.

10. Li H, Duhachek-Muggy S, Dubnicka S and Zolkiewska A: Metalloproteinase-disintegrin ADAM12 is associated with a breast tumor-initiating cell phenotype. Breast Cancer Res Treat 139: 691-703, 2013.

11. Rao VH, Vogel K, Yanagida JK, Marwaha N, Kandel A, Trempus C, Repertinger SK and Hansen LA: Erbb2 up-regulation of ADAM12 expression accelerates skin cancer progression. Mol Carcinog 54: 1026-1036, 2015.

12. Cheon DJ, Li AJ, Beach JA, Walts AE, Tran H, Lester J, Karlan BY and Orsulic S: ADAM12 is a prognostic factor associated with an aggressive molecular subtype of high-grade serous ovarian carcinoma. Carcinogenesis 36: 739-747, 2015.

13. Carl-McGrath S, Lendeckel U, Ebert M, Roessner A and Röcken C: The disintegrin-metalloproteinases ADAM9, ADAM12, and ADAM15 are upregulated in gastric cancer. Int J Oncol 26: 17-24, 2005.

14. Mino N, Miyahara R, Nakayama E, Takahashi T, Takahashi A, Iwakiri S, Sonobe M, Okubo K, Hirata T, Sehara A and Date H: A disintegrin and metalloprotease 12 (ADAM12) is a prognostic factor in resected pathological stage I lung adenocarcinoma. J Surg Oncol 100: 267-272, 2009.

15. Peduto L, Reuter VE, Sehara-Fujisawa A, Shaffer DR, Scher HI and Blobel CP: ADAM12 is highly expressed in carcinoma-associated stroma and is required for mouse prostate tumor progression. Oncogene 25: 5462-5466, 2006.

16. Kodama T, Ikeda E, Okada A, Ohtsuka T, Shimoda M, Shiomi T, Yoshida K, Nakada M, Ohuchi E and Okada Y: ADAM12 is selectively overexpressed in human glioblastomas and is associated with glioblastoma cell proliferation and shedding of heparin-binding epidermal growth factor. Am J Pathol 165: 1743-1753, 2004.

17. Rao VH, Kandel A, Lynch D, Pena Z, Marwaha N, Deng C, Watson P and Hansen LA: A positive feedback loop between HER 2 and ADAM12 in human head and neck cancer cells increases migration and invasion. Oncogene 31: 2888-2898, 2012.

18. Georges S, Chesneau J, Hervouet S, Taurelle J, Gouin F, Redini F, Padrines M, Heymann D, Fortun Y and Verrecchia F: A disintegrin and metalloproteinase 12 produced by tumour cells accelerates osteosarcoma tumour progression and associated osteolysis. Eur J Cancer 49: 2253-2263, 2013.

19. Roy R and Moses MA: ADAM12 induces estrogen-independence in breast cancer cells. Breast Cancer Res Treat 131: 731-741, 2012.

20. Klionsky DJ: Autophagy revisited: A conversation with Christian de Duve. Autophagy 4: 740-743, 2008.

21. Mizushima N and Komatsu M: Autophagy: Renovation of cells and tissues. Cell 147: 728-741, 2011.

22. Kobayashi S: Choose delicately and reuse adequately: The newly revealed process of autophagy. Biol Pharm Bull 38: 1098-1103, 2015.

23. Eisenberg-Lerner A, Bialik S, Simon HU and Kimchi A: Life and death partners: apoptosis, autophagy and the cross-talk between them. Cell Death Differ 16: 966-975, 2009.

24. White E and DiPaola RS: The double-edged sword of autophagy modulation in cancer. Clin Cancer Res 15: 5308-5316, 2009.

25. Thorburn A: Apoptosis and autophagy: Regulatory connections between two supposedly different processes. Apoptosis 13: 1-9, 2008.

26. Doherty J and Baehrecke EH: Life, death and autophagy. Nat Cell Biol 20: 1110-1117, 2018

27. Tan Z, Zhang Y, Deng J, Zeng G and Zhang Y: Purified vitexin compound 1 suppresses tumor growth and induces cell apoptosis in a mouse model of human choriocarcinoma. Int J Gynecol Cancer 22: 360-366, 2012.

28. Deng J, Zhang Y and Tan Z: Proliferation and apoptosis of choriocarcinoma cell JEG-3 induced by VB2 and its in vitro mechanism. Zhong Nan Da Xue Xue Bao Yi Xue Ban 38: 476-782, 2013 (In Chinese).

29. Peng Z,Zhang C,Zhou W, Wu C and Zhang Y: The STAT3/NFIL3 signaling axis-mediated chemotherapy resistance is reversed by Raddeanin A via inducing apoptosis in choriocarcinoma cells. J Cell Physiol 233: 5370-5382, 2018.

30. Wu C, Yu S, Tan Q, Guo P and Liu H: Role of AhR in regulating cancer stem cell-like characteristics in choriocarcinoma. Cell Cycle 17: 2309-2320, 2018.

31. Shi D, Zhang Y, Lu R and Zhang Y: The long non-coding RNA MALAT1 interacted with miR-218 modulates choriocarcinoma growth by targeting Fbxw8. Biomed Pharmacother 97: 543-550, 2018 . 
32. Cheng CJ, Bahal R, Babar IA, Pincus Z, Barrera F, Liu C, Svoronos A, Braddock DT, Glazer PM, Engelman DM, et al: MicroRNA silencing for cancer therapy targeted to the tumour microenvironment. Nature 518: 107-110, 2015.

33. Denton D, Nicolson S and Kumar S: Cell death by autophagy: Facts and apparent artefacts. Cell Death Differ 19: 87-95, 2012.

34. Anding AL and Baehrecke EH: Autophagy in cell life and cell death. Curr Top Dev Biol 114: 67-91, 2015.

35. Arakawa S, Tsujioka M, Yoshida T, Tajima-Sakurai H, Nishida Y, Matsuoka Y, Yoshino I, Tsujimoto Y and Shimizu S: Role of Atg5-dependent cell death in the embryonic development of Bax/Bak double-knockout mice. Cell Death Differ 24: 1598-1608, 2017.

36. Shimizu S, Kanaseki T, Mizushima N, Mizuta T, Arakawa-Kobayashi S, Thompson CB and Tsujimoto Y: Role of Bcl-2 family proteins in a non-apoptotic programmed cell death dependent on autophagy genes. Nat Cell Biol 6: 1221-1228, 2004

37. Lamy L, Ngo VN, Emre NC, Shaffer AL III, Yang Y, Tian E, Nair V, Kruhlak MJ, Zingone A, Landgren O and Staudt LM: Control of autophagic cell death by caspase-10 in multiple myeloma. Cancer Cell 23: 435-449, 2013.

38. Yu L, Alva A, Su H, Dutt P, Freundt E, Welsh S, Baehrecke EH and Lenardo MJ: Regulation of an ATG7-beclin 1 program of autophagic cell death by caspase-8. Science 304: 1500-1502, 2004

39. Elgendy M, Sheridan C, Brumatti G and Martin SJ: Oncogenic Ras-induced expression of Noxa and Beclin-1 promotes autophagic cell death and limits clonogenic survival. Mol Cell 42: 23-35, 2011.

40. Byun JY, Yoon CH, An S, Park IC, Kang CM, Kim MJ and Lee SJ: The Rac1/MKK7/JNK pathway signals upregulation of Atg5 and subsequent autophagic cell death in response to oncogenic Ras. Carcinogenesis 30: 1880-1888, 2009.

41. Dasari SK, Bialik S, Levin-Zaidman S, Levin-Salomon V, Merrill AH Jr, Futerman AH and Kimchi A: Signalome-wide RNAi screen identifies GBA1 as a positive mediator of autophagic cell death. Cell Death Differ 24: 1288-1302, 2017.

42. Debnath J, Baehrecke EH and Kroemer G: Does autophagy contribute to cell death? Autophagy 1: 66-74, 2005.

43. Dalby KN, Tekedereli I, Lopez-Berestein G and Ozpolat B: Targeting the prodeath and prosurvival functions of autophagy as novel therapeutic strategies in cancer. Autophagy 6: 322-329, 2010.

44. Susin SA, Lorenzo HK, Zamzami N, Marzo I, Snow BE Brothers GM, Mangion J, Jacotot E, Costantini P, Loeffler M, et al: Molecular characterization of mitochondrial apoptosis-inducing factor. Nature 397: 441-446, 1999.

45. Chen W, Li N, Chen T, Han Y, Li C, Wang Y, He W, Zhang L, Wan $\mathrm{T}$ and Cao X: The lysosome-associated apoptosis-inducing protein containing the pleckstrin homology $(\mathrm{PH})$ and FYVE domains (LAPF), representative of a novel family of PH and FYVE domain-containing proteins, induces caspase-independent apoptosis via the lysosomal-mitochondrial pathway. J Biol Chem 280: 40985-40995, 2005.

46. Chen D, Zheng X, Kang D, Yan B, Liu X, Gao Y and Zhang K Apoptosis and expression of the Bcl-2 family of proteins and P53 in human pancreatic ductal adenocarcinoma. Med Princ Pract 21: 68-73, 2012

47. Gursan N, Karakök M, Sari I and Gursan MS: The relationship between expression of $\mathrm{p} 53 / \mathrm{Bcl}-2$ and histopathological criteria in breast invasive ductal carcinomas. Int J Clin Pract 55: 589-590, 2001

48. Hemann MT and Lowe SW: The p53-Bcl-2 connection. Cell Death Differ 13: 1256-1259, 2006

49. Wesselborg S and Stork B: Autophagy signal transduction by ATG proteins: From hierarchies to networks. Cell Mol Life Sci 72: 4721-4757, 2015.

50. Pyo JO, Jang MH, Kwon YK, Lee HJ, Jun JI, Woo HN, Cho DH, Choi B, Lee H, Kim JH, et al: Essential roles of Atg5 and FADD in autophagic cell death: Dissection of autophagic cell death into vacuole formation and cell death. J Bio Chem 280: 20722-20729, 2005.

51. Mehrpour M, Esclatine A, Beau I and Codogno P: Overview of macroautophagy regulation in mammalian cells. Cell Res 20 : $748-762,2010$

52. Otomo C, Metlagel Z, Takaesu G and Otomo T: Structure of the human ATG12 ATG5 conjugate required for LC3 lipidation in autophagy. Nat Struct Mol Biol 20: 59-66, 2013.

53. Cadwell K, Stappenbeck TS and Virgin HW: Role of autophagy and autophagy genes in inflammatory bowel disease. Curr Top Microbiol Immunol 335: 141-167, 2009.

54. Fésüs L, Demény MÁ and Petrovski G: Autophagy shapes inflammation. Antioxid Redox Signal 14: 2233-2243, 2011.

55. Levine B, Mizushima N and Virgin HW: Autophagy in immunity and inflammation. Nature 469: 323-335, 2011.
56. Chen YM, Chang CY, Chen HH, Hsieh CW, Tang KT, Yang MC, Lan JL and Chen DY: Association between autophagy and inflammation in patients with rheumatoid arthritis receiving biologic therapy. Arthritis Res Ther 20: 268, 2018.

57. Saitoh $T$ and Akira $S$ : Regulation of innate immune responses by autophagy-related proteins. J Cell Biol 189: 925-935, 2010.

58. Deretic V: Multiple regulatory and effector roles of autophagy in immunity. Curr Opin Immunol 21: 53-62, 2009.

59. Harris J: Autophagy and cytokines. Cytokine 56: 140-144, 2011.

60. Harris J and Keane J: How tumour necrosis factor blockers interfere with tuberculosis immunity. Clin Exp Immunol 161: 1-9, 2010

61. Yang R, Zhang Y, Wang L, Hu J, Wen J, Xue L, Tang M, Liu Z and $\mathrm{Fu} \mathrm{J}$ : Increased autophagy in fibroblast-like synoviocytes leads to immune enhancement potential in rheumatoid arthritis. Oncotarget 8: 15420-15430, 2017.

62. Harris J, Lang T, Thomas JPW, Sukkar MB, Nabar NR and Kehrl JH: Autophagy and inflammasomes. Mol Immunol 86: 10-15, 2017.

63. Shi CS, Shenderov K, Huang NN, Kabat J, Abu-Asab M, Fitzgerald KA, Sher A and Kehrl JH: Activation of autophagy by inflammatory signals limits IL- $1 \beta$ production by targeting ubiquitinated inflammasomes for destruction. Nat Immunol 13: 255-263, 2012.

64. Morselli E, Galluzzi L, Kepp O, Vicencio JM, Criollo A, Maiuri MC and Kroemer G: Anti- and pro-tumor functions of autophagy. Biochim Biophys Acta 1793: 1524-1532, 2009.

65. Wu H and Lozano G: NF-kappa B activation of p53. A potential mechanism for suppressing cell growth in response to stress. J Biol Chem 269: 20067-20074, 1994.

66. Catz SD and Johnson JL: Transcriptional regulation of bcl-2 by nuclear factor kappa B and its significance in prostate cancer. Oncogene 20: 7342-7351, 2001

67. Grimm S, Bauer MK, Baeuerle PA and Schulze-Osthoff K: Bcl-2 down-regulates the activity of transcription factor NF-kappaB induced upon apoptosis. J Cell Biol 134: 13-23, 1996.

68. Boakye YD, Groyer L and Heiss EH: An increased autophagic flux contributes to the anti-inflammatory potential of urolithin $\mathrm{A}$ in macrophages. Biochim Biophys Acta Gen Subj 1862: 61-70, 2018.

69. Liu T, Zhang L, Joo D and Sun SC: NF- $\mathrm{B}$ signaling in inflammation. Signal Transduct Target Ther 2: pii: 17023, 2017.

70. Davignon JL, Hayder M, Baron M, Boyer JF, Constantin A, Apparailly F, Poupot R and Cantagrel A: Targeting monocytes/macrophages in the treatment of rheumatoid arthritis. Rheumatology (Oxford) 52: 590-598, 2013.

71. Ip WKE, Hoshi N, Shouval DS, Snapper S and Medzhitov R: Anti-inflammatory effect of IL-10 mediated by metabolic reprogramming of macrophages. Science 356: 513-519, 2017.

72. Ko JH, Yoon SO, Lee HJ and Oh JY: Rapamycin regulates macrophage activation by inhibiting NLRP3 inflammasome-p38 MAPK-NF $\kappa$ B pathways in autophagy- and p62-dependent manners. Oncotarget 8: 40817-40831, 2017.

73. Inoki K and Guan KL: Complexity of the TOR signaling network. Trends Cell Biol 16: 206-212, 2006.

74. Reiling JH and Sabatini DM: Stress and mTORture signaling. Oncogene 25: 6373-6383, 2006.

75. Sarbassov DD, Ali SM and Sabatini DM: Growing roles for the mTOR pathway. Curr Opin Cell Biol 17: 596-603, 2005.

76. Wu YT, Tan HL, Shui G, Bauvy C, Huang Q, Wenk MR, Ong CN, Codogno P and Shen HM: Dual role of 3-methyladenine in modulation of autophagy via different temporal patterns of inhibition on class I and III phosphoinositide 3-kinase. J Biol Chem 285: 10850-10861, 2010.

77. Jung CH, Ro SH, Cao J, Otto NM and Kim DH: mTOR regulation of autophagy. FEBS Lett 584: 1287-1295, 2010.

78. Kim YC and Guan KL: mTOR: A pharmacologic target for autophagy regulation. J Clin Invest 125: 25-32, 2015.

79. Paquette M, EI-Houjeiri L and Pause A: mTOR pathways in cancer and autophagy. Cancers (Basel) 10: pii: E18, 2018

80. Dunlop EA and Tee AR: mTOR and autophagy: A dynamic relationship governed by nutrients and energy. Semin Cell Dev Biol 36: 121-129, 2014

81. Nah J, Yuan J and Jung YK: Autophagy in neurodegenerative diseases: From mechanism to therapeutic approach. Mol Cells 38: 381-389, 2015.

82. Guo F, Liu X, Cai H and Le W: Autophagy in neurodegenerative diseases: Pathogenesis and therapy. Brain Pathol 28: 3-13, 2018.

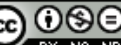

This work is licensed under a Creative Commons Attribution-NonCommercial-NoDerivatives 4.0 International (CC BY-NC-ND 4.0) License. 